\title{
Stroke Genetics: A Review and Update
}

\author{
Arne Lindgren ${ }^{\mathrm{a}, \mathrm{b}}$ \\ ${ }^{a}$ Department of Clinical Sciences Lund, Neurology, Lund University, Lund, Sweden \\ ${ }^{b}$ Department of Neurology and Rehabilitation Medicine, Skane University Hospital, Lund, Sweden
}

Stroke genetics includes several topics of clinical interest, including (1) molecular genetic variations affecting risk of monogenic stroke syndromes; (2) molecular genetic variations affecting risk of common stroke syndromes, sometimes with specific effects on risk of specific main types of stroke or subtypes of ischemic and hemorrhagic stroke; (3) genetics of conditions associated with stroke risk e.g. white matter hyperintensities, atrial fibrillation and hypertension; (4) hereditary causes of familial aggregation of stroke; (5) epigenetic impact on protein expression during acute brain injury; (6) genetic influence on stroke recovery; and (7) pharmacogenetics. Genetic research methods include candidate gene studies; Genome Wide Association Studies; family studies; RNA and protein analyses; and advanced computer-aided analytical methods to detect statistically significant associations. Several methods that could improve our knowledge of stroke genetics are being developed e.g.: Exome content analysis; Next-generation sequencing; Whole genome sequencing; and Epigenetics. During 2012-2014, several Single Nucleotide Polymorphisms (SNPs) have been related to common ischemic stroke risk. Certain SNPs have been associated with risk of specific ischemic stroke subtypes such as large vessel disease and cardiac embolism, particular subtypes of intracerebral hemorrhage (ICH), especially lobar $\mathrm{ICH}$, and with prognosis after $\mathrm{ICH}$. Large international studies on stroke recovery and exome content are ongoing. Advanced mathematical models have been used to study how several SNPs can act together and increase stroke risk burden. Such efforts require large numbers of patients and controls, which is achieved by co-operation in large international consortia such as the International Stroke Genetics Consortium. This overview includes an introduction to genetics, stroke genetics in general, and different genetic variations that may influence stroke risk. It presents some of the latest reports on stroke genetics published in high impact journals. The role of pharmacogenetics, the current clinical situation, and future prospects will also be discussed.

\author{
Correspondence: Arne Lindgren \\ Department of Neurology, Skåne \\ University Hospital, SE-221 85 Lund, \\ Sweden \\ Tel: +4646171424 \\ E-mail: arne.lindgren@med.lu.se
}

Received: September 1, 2014 Revised: September 24, 2014 Accepted: September 25, 2014

The author has no financial conflicts of interest.

\section{Introduction}

\section{The human genome}

The human genome consists of 23 chromosome pairs i.e. in total 46 chromosomes. The DNA of these chromosomes contain about 6 billion base pairs. ${ }^{1}$ The genome can be divided into the exon part, called the exome. This is the $1.5 \%$ of DNA that contains approximately 25,000 genes coding for about 100,000 proteins in humans. ${ }^{2}$ The intron part is not coding for proteins but has regulatory properties. In addition, there is also mitochondrial DNA containing approximately 16,000 base pairs with 13 protein coding genes. ${ }^{3}$ Each human cell contains hundreds or thousands of sets of this mitochondrial DNA. ${ }^{3}$ 


\section{Genetic variation}

Genetic variation in humans may have several causes. The DNA in the genome itself can be altered. Epigenetic factors can influence the gene expression through variations in DNA methylation and variations of histones - proteins controlling the DNA string formation. DNA changes range from large alterations of a part of or of a whole chromosome - cytogenetic changes that are possible to detect on microscopic chromosomal examination and sometimes not compatible with life. Alterations of intermediate size are on a submicroscopic level. The smallest molecular changes are confined to variation of one single base pair - a Single Nucleotide Polymorphism (SNP) where a nucleotide has been exchanged for another (Figure 1). Even though there are about 6 billion base pairs, only about 78 million - i.e. a small proportion of these base pairs have variations described as SNPs. ${ }^{4}$ Today's clinical molecular research is often heavily focused on SNP analyses and there is a risk that other alterations therefore remain unnoticed. It should therefore be kept in mind that other molecular DNA changes such as copy number variants (CNVs), repeats, insertions, deletions and microsatellites may also account for clinical genetic variation. Another question is how several variations may interact with each other and there is a need for advanced mathematical analytical methods utilizing powerful computer techniques to investigate such associations.

It should also be considered how common a genetic variation is and how common the disease studied is. For a common stroke phenotype the genetic variant can be common, rare, or even private i.e. confined to one individual or family. The impact of the genetic variant may differ considerably: with a high penetrance and importance it may cause a monogenic syndrome, with less influence it may still contribute to commonly occurring disorders with a more complex heritability.

\section{Molecular genetic studies of stroke risk}

One to two decades ago, molecular studies were often conducted as linkage studies where markers such as microsatellites were used to identify areas related to risk. As an example, one study using microsatellite markers and SNP analyses reported a possible association between stroke and variations in the $P D$ E4D gene. ${ }^{5}$

An era of candidate gene studies followed the linkage studies. The idea is that by a logical and educated guess a candidate gene can be suggested as possibly related to variation in stroke risk. Numerous studies on this have been published, but many studies have been unsuccessful or not been possible to repeat. Genes of interest have included e.g. $P D E 4 D^{6}$ and genes associated with cardiovascular disease. ${ }^{7,8}$ Many of the candidate gene studies have been on specific SNPs in the area of interest in the genome.

During the last decade many genome wide association studies (GWAS) have been performed. In a GWAS, an agnostic approach is used. A large number of SNPs, often in the range of 500,000 to 5,000,000 are examined throughout the whole chromosomal genome. Because so many SNPs are examined at the same time an adjustment for multiple testing has to be done. Therefore a $\mathrm{p}$ value threshold of $5 \times 10^{-8}$ - corresponding to a Bonferroni correction for $1,000,000$ tests - is often set as a sig-

- Whole chromosomal and whole genome changes: 1-6 billion bp

- Aneuploidy (abnormal number of chromosomes)

Aneusomy (fewer or more copies than 2 of a chromosome)

- Interchromosomal translocations

- Ring chromosomes

- Microscopic to submicroscopic

- Segmental aneusomoy

- Chromosomal deletions

- Chromosomal insertions

- Chromosal inversions

- Intrachromosomal translocations

- Chromosomal abnormality

- Fragile sites

- $1 \mathrm{~kb}$ to submicroscopic

- Copy number variants (CNVs)

- Segmental duplications

- Inversions, translocations

- CNV regions

- Microdeletions

- Microduplications

- 2 bp to 1,000 bp

- Microsatellites, minisatellites

- Insertion-deletions (Indels)

- Inversions

- Di-, tri-, tetra-nucleotide repeats

- Variable number tandem repeats e.g. microsatellites

- $\quad$ Single nucleotide $1 \mathrm{bp}$

- Indels

- SNPS

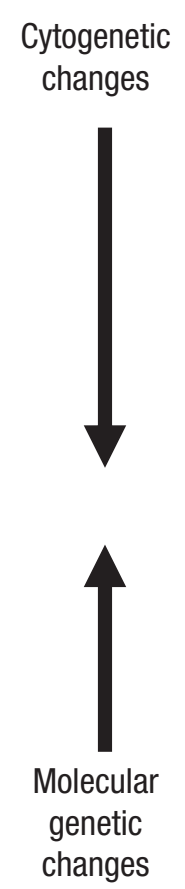

Figure 1. Examples of DNA variations in the human genome. 
Table 1. Examples of published results from genome-wide studies, showing SNPs related to ischemic stroke risk

\begin{tabular}{lccc}
\hline SNP in chromosome & Gene region & Relation to & Reference \\
\hline 4q25 & PITX2 & CE, All IS & $12-14$ \\
7p21 & HDAC9 & LVD, All IS & $13-15$ \\
6p21.1 & SUPT3H/CDC5L & LVD & 16 \\
9p21 & CDKN2A/CDKN2B/ANRIL & LVD, All IS & 13,17 \\
9q34 & ABOblood locus & LVD and CE & 18 \\
$11 q 22$ & MMP12 & LVD & 19 \\
12p13.33 & NINJ & All IS & 20 \\
12q24.12 & NAA25/C12orf30 & All IS & 14 \\
16q22 & ZFHX3 & CE & 13,21 \\
\hline
\end{tabular}

LVD, large vessel disease; CE, Cardioembolic Embolism; IS, Ischemic stroke.

nificance level for GWAS investigations. It could be questioned whether this level should always be the same or if it should be adjusted because of e.g. the actual number of SNPs being analyzed. GWAS examinations have now yielded several very interesting results for ischemic stroke risk (Table 1). More studies are ongoing. ${ }^{9}$ Several overviews on stroke genetics have recently been published. ${ }^{10,11}$

\section{Molecular genetic variations affecting risk of monogenic stroke syndromes}

Today, there are several monogenic stroke syndromes that have been related to molecular genetic variation. Examples of monogenetic stroke syndromes are given in Table 2. Comprehensive accounts of have been published..$^{11,22,23}$ Information on the Internet is available at e.g. Genetics Home Reference at http: //ghr.nlm.nih.gov/.

\section{Molecular genetic variations affecting risk of common stroke syndromes, sometimes with specific effects on specific main types of stroke or subtypes of ischemic and hemorrhagic stroke}

\section{Ischemic stroke}

The three main ischemic stroke syndromes: large vessel disease, cardioembolic stroke and small vessel disease have been studied separately regarding genetic risk. Several molecular genetic variations have been reported to be related to large artery disease and to cardioembolic stroke (Table 1). Some findings have been reported in several studies e.g. HDAC9 related to large vessel disease $\mathrm{e}^{13,15}$ and PITX2 and ZFHX3 related to cardioembolic stroke. ${ }^{13,14}$ The effect sizes of the identified SNPs have been modest; e.g. for a HDAC9 variant and stroke related to large vessel disease: odds ratio $(\mathrm{OR})=1.42$ (95\% confidence interval $[\mathrm{CI}]=1.28-1.57)$; and a PITX2 variant and cardioembolic stroke OR1.32 (95\% CI=1.20-1.46). ${ }^{15}$ One observation is that the GWAS detected variations related to common ischemic stroke caused by small vessel disease have been fewer or absent in GWAS studies of ischemic stroke. The explanation for this is unknown but it has been suggested that small vessel disease may represent several different phenotypes and thus be a more heterogeneous condition ${ }^{24}$ and also be subject to different definitions, ${ }^{25}$ whereas large artery disease and cardioembolic stroke may be less heterogeneous. The relation of genetic variants to overall ischemic stroke has also been reported but with less consistency. There is a trade-off between very specific phenotyping e.g. defined types of ischemic stroke and the number of subjects that can be included in the genetic studies. It seems clear today that ischemic stroke is not caused by one common pathogenetic factor, however there seems to be considerable overlap between the different subtypes of ischemic stroke regarding risk factors such as e.g. hypertension. It has been shown that a risk score taking several genetic variations related to ischemic stroke risk into account is associated with ischemic stroke overall. $^{26}$

\section{Intracerebral hemorrhage (ICH)}

Also hemorrhagic stroke risk has been related to genetic variations (Table 3). The risk of lobar intracerebral hemorrhage has been firmly related to variations in the APOE gene, especially the $\varepsilon 2$ or $\varepsilon 4$ alleles. There are indications that although variations in the COL $4 A 1$ region have been related to monogenic related $\mathrm{ICH}$, other variations in the same region may be related to a somewhat increased risk of sporadic $\mathrm{ICH} .{ }^{27}$ A detailed description of genetic risk of sporadic ICH has recently been published. ${ }^{11}$

\section{Genetics of conditions associated with stroke risk - intermediate phenotypes - e.g. white matter hyperintensities, atrial fibrillation, and hypertension}

Several intermediate phenotypes are related to stroke risk and it is therefore of interest if genetic risk for these phenotypes is also associated with increased stroke risk either independently or through the intermediate phenotype. As mentioned above, a genetic risk score considering genetic variations linked to intermediate phenotypes related to stroke has been associated with overall risk of ischemic stroke. ${ }^{26}$ The same reference contains a comprehensive supplemental table listing genes related to intermediate phenotypes indicating stroke risk. Another study reported that a risk score including genetic variations related to stroke and its risk factors could improve the prediction of future stroke compared 
Table 2. Examples of monogenetic stroke syndromes

\begin{tabular}{|c|c|c|c|c|}
\hline Syndrome & Abbreviation & Chromosome & Gene region & Symptoms \\
\hline $\begin{array}{l}\text { Cerebral autosomal dominant subcortical } \\
\text { infarcts and leukoencephalopathy }\end{array}$ & CADASIL & 19p13.2-p13.1 & NOTCH3 & Migraine, cognitive problems, depression, seizures, stroke \\
\hline $\begin{array}{l}\text { Cerebral autosomal recessive arteriopathy } \\
\text { with subcortical infarcts and } \\
\text { leukoencephalopathy }\end{array}$ & CARASIL & $10 \mathrm{q} 26.3$ & HTRA1 & Spasticity, stroke, cognitive problems, scalp hair loss, back pain \\
\hline Fabry disease & & $x$ & GLA & $\begin{array}{l}\text { Episodes of pain in hands and feet, angiokeratomas, corneal opacity, } \\
\text { renal affection, heart affection, stroke }\end{array}$ \\
\hline Sickle cell disease & & $11 \mathrm{p} 15.5$ & $H B B$ & $\begin{array}{l}\text { Anemia, pain episodes, infections, affection of lungs including } \\
\text { pulmonary hypertension, kidneys, spleen, and brain including stroke }\end{array}$ \\
\hline $\begin{array}{l}\text { Hereditary endotheliopathy with } \\
\text { retinopathy, nephropathy and stroke }\end{array}$ & HERNS & $3 p 21.31$ & TREX1 & Visual loss, cognitive problems, stroke-like episodes, renal dysfunction \\
\hline Marfan syndrome & & $15 q 21.1$ & FBN1 & $\begin{array}{l}\text { Lens dislocation, cataract, myopia, aortic aneurysm, aortic dissection, } \\
\text { cerebral aneurysms, cerebral hemorrhage, arthritis, tall habitus, } \\
\text { pectus excavatum, dural ectasia }\end{array}$ \\
\hline Ehlers Danlos syndrome type IV & & $2 q 31$ & COL3A1 & $\begin{array}{l}\text { Joint hypermobility, cerebral aneurysm, arterial dissection, short stature, } \\
\text { thin skin that easily bruises, intestinal and uterine fragility, joint } \\
\text { subluxation and pain }\end{array}$ \\
\hline Pseudoxanthoma elasticum & & 16p13.1 & ABCC6 & $\begin{array}{l}\text { Papules in flexor areas of skin, visual loss, hypertension, } \\
\text { arterial dissection }\end{array}$ \\
\hline Homocystinuria & & $\begin{array}{l}\text { 21q22.3, 1p36.3 } \\
\text { and other }\end{array}$ & $\begin{array}{l}\text { CBS, MTHFR, } \\
\text { and other }\end{array}$ & $\begin{array}{l}\text { Varies. E.g. cognitive problems, myopia, lens dislocation, osteoporosis, } \\
\text { thromboembolic events }\end{array}$ \\
\hline $\begin{array}{l}\text { Neurofibromatosis type } 1 \\
\text { (von Recklinghausen's disease) }\end{array}$ & & $17 q 11.2$ & NF1 & $\begin{array}{l}\text { Café-au-lait skin spots, neurofibromas, optic glioma, cerebral ischemia, } \\
\text { intracranial aneurysm }\end{array}$ \\
\hline von Hippel-Lindau syndrome & & 3p25.3 & VHL & $\begin{array}{l}\text { Hemangioblastoma in brain, spinal cord, retina. Intracerebral } \\
\text { hemorrhage, pheochromocytoma, hearing loss }\end{array}$ \\
\hline COL4A1-related brain small vessel disease & & $13 q 34$ & COL4A1 & Hemorrhagic stroke, white matter changes, seizures, migraine \\
\hline $\begin{array}{l}\text { Hereditary hemorrhagic telangiectasia } \\
\text { (Osler-Weber-Rendu disease) }\end{array}$ & & Several & Several & $\begin{array}{l}\text { Telangiactasia, arteriovenous malformaitons in lungs, brain, liver } \\
\text { intestines. Intracerebral hemorrhage. Ischemic stroke }\end{array}$ \\
\hline Hereditary cerebral amyloid angiopathy & & $\begin{array}{l}21 \mathrm{q} 21.3 \\
\text { and other }\end{array}$ & APP and other & $\begin{array}{l}\text { Lobar intracerebral hemorrhage, cerebral microbleeds, cognitive } \\
\text { problems }\end{array}$ \\
\hline Familial cerebral arterial aneurysms & & Several & Several & $\begin{array}{l}\text { May be associated with other syndromes eg Marfan syndrome, } \\
\text { Polycystic kidney disease }\end{array}$ \\
\hline Cerebral cavernous malformations & & $\begin{array}{l}\text { 7q21.2,7p13 } \\
\text { and other }\end{array}$ & $\begin{array}{l}\text { KRIT1, CCM2 } \\
\text { and other }\end{array}$ & $\begin{array}{l}\text { Cerebral hemorrhage, seizures, brainstem symptoms, cranial nerve } \\
\text { symptoms }\end{array}$ \\
\hline $\begin{array}{l}\text { Mithochondrial encephalopathy lactic } \\
\text { acidosis and strokelike episodes }\end{array}$ & MELAS & Mitochondrial DNA & Several & Muscle weakness, headache episodes, seizures, strokelike episodes \\
\hline
\end{tabular}

Table 3. Examples of SNPS related to ICH risk

\begin{tabular}{lccc}
\hline SNP in chromosome & Gene region & Relation to & Reference \\
\hline 19q13 & APOE & Lobar ICH & 28 \\
1q22 & $P M F 1 / S L C 25 A 44$ & Non-lobar ICH & 29 \\
13q34 & COL4A1 & ICH & 27 \\
6p21 & KCNK17 & ICH & 30 \\
\hline
\end{tabular}

SNP, single nucleotide polymorphism; ICH, intracerebral hemorrhage.

with using a risk score based only on clinical information. ${ }^{31}$ Some intermediate phenotypes are discussed in more detail below.

\section{White matter hyperintensities (WMH)}

The presence of white matter lesions has been related to stroke risk. ${ }^{32,33}$ Therefore it is possible that genetic changes resulting in WMH may also result in increased risk of stroke. The heritability of cerebral white matter hyperintensities is high. ${ }^{34} \mathrm{An}$ associa- tion between the 17q25 locus and white matter hyperintensity volume has been reported. ${ }^{35,36}$ This association has also been reported in subjects with stroke although there was not a clear relation to the presence of small vessel disease manifested as lacunar infarction. ${ }^{37}$ It is likely that several different genetic variations contribute to the risk of WMH and a recent study of patients with CADASIL reported a polygenic risk score for WMH volume, illustrating that examination of a subgroup of individuals with high likelihood of a condition can be used to detect additional traits contributing to risk of the condition. ${ }^{38}$ ApoE $\varepsilon 4$ carriers have been reported to have higher subcortical white matter lesion volume. ${ }^{39}$ However, the effect of the APOE $\varepsilon 4$ allele on white matter integrity is uncertain. ${ }^{40}$ Variations in the $\mathrm{NOTCH} 3$ gene may also influence the risk of WMH or small vessel disease in individuals without the typical CADASIL syndrome. $^{41}$ 


\section{Atrial fibrillation (AF)}

Several genes have been related to $\mathrm{AF}^{42-44}$ The mechanisms through which these genes contribute to AF risk are largely unknown although a recent study showed a relation between some of these genes and prolonged atrial action potential duration in an animal model. ${ }^{43}$ It seems as if adding a genetic risk score of gene variations related to $\mathrm{AF}$ in patients with $\mathrm{AF}$ improves the risk assessment for stroke in addition to the often used $\mathrm{CHADS}_{2}$ score in these patients. ${ }^{45}$

\section{Hypertension}

Hypertension is one of the most important risk factors for stroke, both ischemic and hemorrhagic. Blood pressure has heritability estimates of $30 \%-50 \%{ }^{46}$ Several genes have been reported to be related to hypertension in GWAS studies of patients without or with stroke. A risk score of 29 such SNPs was related to stroke, not further subtyped, as well as to hypertension and to coronary heart disease. ${ }^{47} \mathrm{It}$ is of interest that an age related effect of genes related to a certain phenotype e.g. blood pressure has been reported ${ }^{48}$ and it is possible that such age related effects are of importance also for other phenotypes including stroke.

In another study, a risk score consisting of $39 \mathrm{SNP}$ associated with blood pressure levels was related to $\mathrm{ICH}$, especially deep ICH rather than lobar ICH, supporting the concept that elevated blood pressure may be more prone to cause deep $\mathrm{ICH}^{49} \mathrm{It}$ was discussed if gene variations influencing blood pressure may be of importance for stroke risk also in individuals with seemingly "normal" blood pressure. ${ }^{49}$

\section{Ischemic heart disease}

The situation for ischemic heart disease (IHD) is similar to that for hypertension. Many traditional risk factors are shared between stroke and IHD. Several genetic variations have been associated with ischemic heart disease. ${ }^{50} \mathrm{~A}$ variation in the chromosome 9p21 region has been related to ischemic stroke. ${ }^{17} \mathrm{~A}$ subsequent follow-up study was not able to find additional variants from the Cardiogram study to be associated with stroke overall or main ischemic stroke subtypes although the number of patients in the individual subtypes were small. ${ }^{7}$ A much larger GWAS study could detect that several genetic variations were shared between ischemic stroke - especially the large artery disease subtype, and coronary heart disease. ${ }^{51}$

It can be expected that in the near future new reports on stroke risk scores including several intermediate phenotypes for stroke risk, also other than discussed above, will be published using more elaborate statistical methods, larger number of genetic variants as well as larger number of individuals. Another method to consider for future studies is that if patients with a very specific phenotype can be detected this may decrease the number of subjects needed to detect genetic influence on cerebrovascular risk as illustrated in the study on CADASIL and WMH volume mentioned above. ${ }^{38}$

\section{Hereditary causes of familial aggregation of stroke}

Apart from molecular analyses, family studies and twin studies are important tools to study heritability of stroke. Such studies clearly indicate heritability of stroke. One study reported a prevalence of stroke or TIA of $12.3 \%$ among first degree relatives of stroke patients compared with $7.5 \%$ among first degree relatives of control subjects. ${ }^{52}$ Another study showed that occurrence of stroke in a parent by 65 years of age was associated with a 3-fold increase in risk of stroke in their offspring. ${ }^{53}$ Twin studies suggest that a genetic component of stroke risk is present. ${ }^{54,55}$ However, subtyping of ischemic stroke and other types of stroke in twin studies would be useful to increase the possibility to better understand heritability of ischemic stroke. ${ }^{56}$

Also GWAS studies have through statistical analyses shown evidence that there is a hitherto unexplained heritability component in the risk of ischemic stroke of about $38 \%$, and that this may vary between different subtypes of ischemic stroke. ${ }^{8}$ Future family studies of stroke should preferably include stroke subtypes and also focus on not only first-degree relatives but also somewhat more distant relatives of the probands.

\section{Epigenetic impact on expression of different proteins before, during and after acute brain injury}

The genetic expression can be influenced by other causes than changes of the DNA content. ${ }^{57}$ Such influences may be referred to as epigenetic mechanisms (Figure 2). One such mechanism is that gene transcription can be regulated by e.g.:

- Methylation of DNA ${ }^{58}$

- Histone modifications ${ }^{58} /$ Histone deacetylases (HDACs)

- Micro-RNA ${ }^{59}$

- Other

It is possible to influence the above mechanisms with pharmacological agents. E.g. valproate is a HDAC inhibitor and has been suggested to perhaps inhibit atherosclerosis. However, much more studies are needed to examine if and how it is possible to treat patients by modifying these mechanisms.

The role of non-protein coding RNA (ncRNA) is intriguing. The DNA coding for ncRNA is in the intronic portion of the genome, which is the vast majority of the DNA. Several classes 


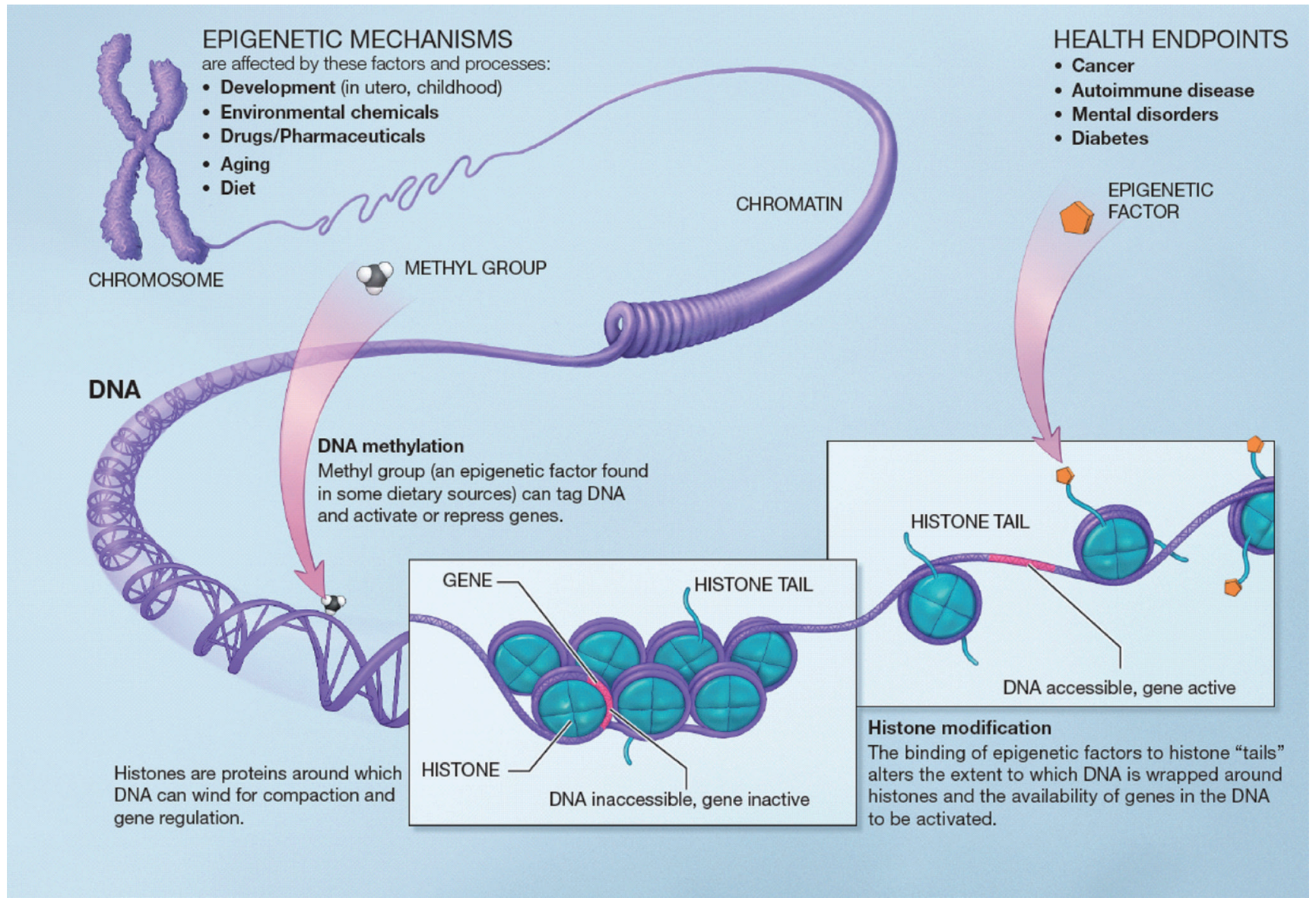

Figure 2. Examples of epigenetic mechanisms. Image courtesy of National Institutes of Health (public domain). http://commonfund.nih.gov/sites/default/files/epigeneticmechanisms.pdf.

of non-protein coding RNA exist, among these micro-RNA. Micro-RNA can regulate gene expression and is considered to be an epigenetic regulator. ${ }^{59}$ Micro-RNA has been suggested to regulate several mechanisms in brain ischemia and therefore be of importance for recovery after stroke. ${ }^{59}$ These regulatory mechanisms may also be involved in the situation of cerebral ischemia with influence on cell death as well as on regeneration after stroke. ${ }^{60}$

The gene expression for coding of different proteins during pathological conditions is of importance for the response of the individual subject. Indeed microarray analyses indicate that there is a very dynamic response varying both with time after stroke as well as between the core and the periinfarct areas of the ischemic area of the brain. ${ }^{61}$ An additional therapeutic epigenetic method suggested is to regulate endogenous or exogenous stem cells to respond to cerebral injury in stroke. ${ }^{62}$

\section{Genetic influence on functional outcome and recovery after stroke}

Recovery after stroke begins immediately after the stroke on- set. Many different biological responses are involved after ischemic stroke and these vary in time and between different areas of the affected brain. ${ }^{63}$ Several of these responses may be of interest from a genetic point of view. These include epigenetic mechanisms - discussed above - that can be targeted for treatment in the varying temporal phases after ischemic stroke onset. $^{60}$

It is also of interest whether genetic variation may influence the possibility and degree of functional outcome after stroke. Different drug therapies have been tried as treatments after stroke but the responses to these therapies vary between patients. E.g. genetic polymorphisms affect the response to L-dopa treatment. ${ }^{64}$ The brain derived neurotrophic factor (BDNF) is involved in brain repair and plasticity and a variation of a SNP (Val66Met) in the BDNF gene has been shown to be related to improved recovery although the early response was in the opposite direction. ${ }^{65}$ The APOE $\varepsilon 4$ has been related to poorer outcome. ${ }^{66}$ Other examples of genes related to functional outcome include $I G F 1,{ }^{67}$ COX-2 and GPIIIa. ${ }^{68}$

After lobar ICH, APOE $\varepsilon 2$ has been related to poorer out- 
come. ${ }^{69}$ But also other genes are of interest for outcome after ICH: an heritability estimate of 90-day ICH mortality for nonAPOE loci using genomewide complex trait analysis has been calculated to about $41 \% .^{70}$

Apart from the study by Devan et al., ${ }^{70}$ all the above mentioned studies on functional outcome and recovery have been candidate gene studies. No large GWAS examining the genetic effect on functional outcome after stroke has been published yet. However, such a study is now ongoing - the Genetics of Ischemic Stroke Functional Outcome Study (GISCOME) and results are expected within the coming year. ${ }^{71}$

\section{Pharmacogenetics}

Pharmacogenetics is a research area holding large promise to be of importance both for stroke and other diseases in the years to come. As has been discussed above, both epigenetics and SNP variations may be used for therapeutic considerations in stroke. Two additional examples are discussed below: Thrombolytic therapy with tissue-type plasminogen activator (tPA) and anticoagulation therapy with warfarin or dabigatran.

\section{Thrombolytic therapy}

A study examined 140 candidate SNPs in 497 tPA-treated ischemic stroke patients and showed that $I L 1 B$ and $v W F$ variants were associated with early recanalization. ${ }^{72}$ The $\nu W F$ variant was also related to FVIII activity in a subsequent functional study. ${ }^{72}$ The same group has published results showing that a genetic variation rs669 (Val1000Ile) in the alpha-2-macroglobulin gene is related to hemorrhagic transformation after tPA treatment. ${ }^{73}$ This indicates that genetic information may possibly be used in the future to predict the response of tPA treatment in ischemic stroke. Such a prediction may help in decision-making regarding iv $\mathrm{TPA}$ or alternative treatments such as endovascular treatment.

\section{Anticoagulation therapy with warfarin or dabigatran}

The treatment with anticoagulants to prevent cardioembolic stroke is highly efficient in a population of individuals with atrial fibrillation and increased risk. However the metabolism of the anticoagulant administered may vary for several reasons where a genetic variation may be one of these. Cytochrome P-450 enzyme CYP2C9 gene variants as well as variants in VKORC1, coding for vitamin $\mathrm{K}$ epoxide reductase (VKOR) are related to warfarin metabolism but the usefulness of genetic testing regarding these variants for guidance on initiation of warfarin treatment has been debated. ${ }^{74}$ The future may lead to other conclusions - in a very recent study association with $A P O E \varepsilon 2$ and $A P$ -
$\mathrm{OE} \varepsilon 4$ for lobar warfarin related $\mathrm{ICH}$ was reported. ${ }^{75}$

In the Randomized Evaluation of Long-term Anticoagulation Therapy (RE-LY) study a GWAS was performed in 2944 RELY patients and showed that the CES1 rs2244613 minor allele was associated with lower active dabigatran metabolite levels. ${ }^{76}$ This minor allele was associated with a lower risk of any bleeding in the dabigatran treated patients but there was no reported association with ischemic events. The value of genetic testing and clopidogrel treatment is also of interest. Clopidogrel is metabolized to its active metabolite by CYP2C19 but the clinical utility for genetic testing to detect influence on CYP3C19 activity is still under debate. ${ }^{77}$

\section{Conclusion}

Stroke genetics today is involved in many fields, including risk, outcome and pharmacogenetics. The research on stroke genetics is progressing with high pace and is expected to continue to do so during the next decade. Stroke subtyping is very important for all these areas. New methods are emerging including detailed exome content analysis, exome sequencing, whole genome sequencing and advanced statistical analytical methods. Large numbers of subjects are often needed in genetic studies and therefore co-operation in international consortia such as the International Stroke Genetics Consortium (ISGC) - www.strokegenetics.org is necessary.

\section{References}

1. Bohlander SK. ABCs of genomics. Hematology Am Soc Hematol Educ Program 2013;2013:316-323.

2. Topol EJ. The genetics of heart attack. Heart 2006;92:855-861.

3. Bogenhagen DF. Mitochondrial DNA nucleoid structure. Biochim Biophys Acta 2012;1819:914-920.

4. ftp://ftp.1000genomes.ebi.ac.uk/vol1/ftp/release/20130502/ README_phase3_callset_20140910. Accessed on Sept 26, 2014.

5. Gretarsdottir S, Thorleifsson G, Reynisdottir ST, Manolescu A, Jonsdottir $\mathrm{S}$, Jonsdottir $\mathrm{T}$, et al. The gene encoding phosphodiesterase 4D confers risk of ischemic stroke. Nat Genet 2003;35:131-138.

6. Lövkvist H, Olsson S, Höglund P, Melander O, Jern C, Sjögren $\mathrm{M}$, et al. A large-sample assessment of possible association between ischaemic stroke and rs12188950 in the PDE4D gene. Eur J Hum Genet 2012;20:783-789.

7. Lövkvist H, Sjögren M, Höglund P, Engström G, Jern C, Olsson S, et al. Are 25 SNPs from the CARDIoGRAM study associated with ischaemic stroke? Eur J Neurol 2013;20:1284-1291. 
8. Bevan S, Traylor M, Adib-Samii P, Malik R, Paul NL, Jackson $\mathrm{C}$, et al. Genetic heritability of ischemic stroke and the contribution of previously reported candidate gene and genomewide associations. Stroke 2012;43:3161-3167.

9. Meschia JF, Arnett DK, Ay H, Brown RD Jr, Benavente OR, Cole JW, et al. Stroke Genetics Network (SiGN) study: design and rationale for a genome-wide association study of ischemic stroke subtypes. Stroke 2013;44:2694-2702.

10. Sharma P, Yadav S, Meschia JF. Genetics of ischaemic stroke. J Neurol Neurosurg Psychiatry 2013;84:1302-1308.

11. Falcone GJ, Malik R, Dichgans M, Rosand J. Current concepts and clinical applications of stroke genetics. Lancet Neurol 2014; 13:405-418.

12. Gretarsdottir S, Thorleifsson G, Manolescu A, Styrkarsdottir U, Helgadottir A, Gschwendtner A, et al. Risk variants for atrial fibrillation on chromosome $4 \mathrm{q} 25$ associate with ischemic stroke. Ann Neurol 2008;64:402-409.

13. Traylor M, Farrall M, Holliday EG, Sudlow C, Hopewell JC, Cheng YC, et al. Genetic risk factors for ischaemic stroke and its subtypes (the METASTROKE collaboration): a meta-analysis of genome-wide association studies. Lancet Neurol 2012; 11:951-962.

14. Kilarski LL, Achterberg S, Devan WJ, Traylor M, Malik R, Lindgren A, et al. Meta-analysis in more than 17,900 cases of ischemic stroke reveals a novel association at 12q24.12. Neurology 2014;83:678-685.

15. International Stroke Genetics Consortium (ISGC); Wellcome Trust Case Control Consortium 2 (WTCCC2), Bellenguez C, Bevan S, Gschwendtner A, Spencer CC, et al. Genome-wide association study identifies a variant in HDAC9 associated with large vessel ischemic stroke. Nat Genet 2012;44:328-333.

16. Holliday EG, Maguire JM, Evans TJ, Koblar SA, Jannes J, Sturm JW, et al. Common variants at 6p21.1 are associated with large artery atherosclerotic stroke. Nat Genet 2012;44:1147-1151.

17. Smith JG, Melander O, Lövkvist H, Hedblad B, Engström G, Nilsson $\mathrm{P}$, et al. Common genetic variants on chromosome 9p21 confers risk of ischemic stroke: a large-scale genetic association study. Circ Cardiovasc Genet 2009;2:159-164.

18. Williams FM, Carter AM, Hysi PG, Surdulescu G, Hodgkiss $\mathrm{D}$, Soranzo $\mathrm{N}$, et al. Ischemic stroke is associated with the $\mathrm{ABO}$ locus: the EuroCLOT study. Ann Neurol 2013;73:16-31.

19. Traylor M, Mäkelä KM, Kilarski LL, Holliday EG, Devan WJ, Nalls MA, et al. A novel MMP12 locus is associated with large artery atherosclerotic stroke using a genome-wide age-at-onset informed approach. PLoS Genet 2014;10:e1004469.

20. Ikram MA, Seshadri S, Bis JC, Fornage M, DeStefano AL, Aulchenko YS, et al. Genomewide association studies of stroke. $N$ Engl J Med 2009;360:1718-1728.
21. Gudbjartsson DF, Holm H, Gretarsdottir S, Thorleifsson G, Walters GB, Thorgeirsson G, et al. A sequence variant in ZFHX3 on $16 \mathrm{q} 22$ associates with atrial fibrillation and ischemic stroke. Nat Genet 2009;41:876-878.

22. Cole JW, Gutwald J. Other monogenetic stroke disorders. In: Sharma P, Meschia J. Stroke Genetics. London: Springer, 2013; 147-170.

23. Uncommon causes of stroke. 2 nd edition. Caplan L (ed). Cambridge: Cambridge University Press, 2008.

24. Federico A, Di Donato I, Bianchi S, Di Palma C, Taglia I, Dotti MT. Hereditary cerebral small vessel diseases: a review. J Neurol Sci 2012;322:25-30.

25. Wardlaw JM, Smith EE, Biessels GJ, Cordonnier C, Fazekas F, Frayne R, et al. Neuroimaging standards for research into small vessel disease and its contribution to ageing and neurodegeneration. Lancet Neurol 2013; 12:822-838.

26. Malik R, Bevan S, Nalls MA, Holliday EG, Devan WJ, Cheng $\mathrm{YC}$, et al. Multilocus genetic risk score associates with ischemic stroke in case-control and prospective cohort studies. Stroke 2014;45:394-402.

27. Weng YC, Sonni A, Labelle-Dumais C, de Leau M, Kauffman WB, Jeanne $M$, et al. COL4A1 mutations in patients with sporadic late-onset intracerebral hemorrhage. Ann Neurol 2012; 71:470-477.

28. Biffi A, Sonni A, Anderson CD, Kissela B, Jagiella JM, Schmidt $\mathrm{H}$, et al. Variants at APOE influence risk of deep and lobar intracerebral hemorrhage. Ann Neurol 2010;68:934-943.

29. Woo D, Falcone GJ, Devan WJ, Brown WM, Biffi A, Howard TD, et al. Meta-analysis of genome-wide association studies identifies 1q22 as a susceptibility locus for intracerebral hemorrhage. Am J Hum Genet 2014;94:511-521.

30. Ma Q, Wang Y, Shen Y, Liu X, Zhu X, Zhang H, et al. The rs 10 947803 SNP of KCNK17 is associated with cerebral hemorrhage but not ischemic stroke in a Chinese population. Neurosci Lett 2013;539:82-85.

31. Ibrahim-Verbaas CA, Fornage M, Bis JC, Choi SH, Psaty BM, Meigs JB, et al. Predicting stroke through genetic risk functions: the CHARGE risk score project. Stroke 2014;45:403-412.

32. Vermeer SE, Hollander M, van Dijk EJ, Hofman A, Koudstaal PJ, Breteler MM. Silent brain infarcts and white matter lesions increase stroke risk in the general population: the Rotterdam scan study. Stroke 2003;34:1126-1129.

33. Gouw AA, van der Flier WM, Fazekas F, van Straaten EC, Pantoni L, Poggesi A, et al. Progression of white matter hyperintensities and incidence of new lacunes over a 3-year period: the Leukoaraiosis and Disability study. Stroke 2008;39:1414-1420.

34. Atwood LD, Wolf PA, Heard-Costa NL, Massaro JM, Beiser A, D’Agostino RB, et al. Genetic variation in white matter hy- 
perintensity volume in the Framingham Study. Stroke 2004;35: 1609-1613.

35. Fornage M, Debette S, Bis JC, Schmidt H, Ikram MA, Dufouil $\mathrm{C}$, et al. Genome-wide association studies of cerebral white matter lesion burden: the CHARGE consortium. Ann Neurol 2011; 69:928-939.

36. Verhaaren BF, de Boer R, Vernooij MW, Rivadeneira F, Uitterlinden AG, Hofman A, et al. Replication study of chr17q25 with cerebral white matter lesion volume. Stroke 2011;42:3297-3299.

37. Adib-Samii P, Rost N, Traylor M, Devan W, Biffi A, Lanfranconi S, et al. 17q25 Locus is associated with white matter hyperintensity volume in ischemic stroke, but not with lacunar stroke status. Stroke 2013;44:1609-1615.

38. Opherk C, Gonik M, Duering M, Malik R, Jouvent E, Hervé $\mathrm{D}$, et al. Genome-wide genotyping demonstrates a polygenic risk score associated with white matter hyperintensity volume in CADASIL. Stroke 2014;45:968-972.

39. de Leeuw FE, Richard F, de Groot JC, van Duijn CM, Hofman A, Van Gijn J, et al. Interaction between hypertension, apoE, and cerebral white matter lesions. Stroke 2004;35:1057-1060.

40. Nyberg L, Salami A. The APOE $\varepsilon 4$ allele in relation to brain white-matter microstructure in adulthood and aging. Scand J Psychol 2014;55:263-267.

41. Schmidt H, Zeginigg M, Wiltgen M, Freudenberger P, Petrovic $\mathrm{K}$, Cavalieri M, et al. Genetic variants of the NOTCH3 gene in the elderly and magnetic resonance imaging correlates of agerelated cerebral small vessel disease. Brain 2011;134(Pt 11):3384 3397.

42. Ellinor PT, Lunetta KL, Albert CM, Glazer NL, Ritchie MD, Smith AV, et al. Meta-analysis identifies six new susceptibility loci for atrial fibrillation. Nat Genet 2012;44:670-675.

43. Sinner MF, Tucker NR, Lunetta KL, Ozaki K, Smith JG, Trompet $S$, et al. Integrating genetic, transcriptional, and functional analyses to identify five novel genes for atrial fibrillation. Circulation 2014 Aug 14. pii: CIRCULATIONAHA.114.009892. [Epub ahead of print].

44. Lubitz SA, Lunetta KL, Lin H, Arking DE, Trompet S, Li G, et al. Novel genetic markers associate with atrial fibrillation risk in Europeans and Japanese. J Am Coll Cardiol 2014;63:12001210.

45. Tada H, Shiffman D, Smith JG, Sjögren M, Lubitz SA, Ellinor PT, et al. Twelve-single nucleotide polymorphism genetic risk score identifies individuals at increased risk for future atrial fibrillation and stroke. Stroke 2014;45:2856-2862.

46. Ehret GB, Caulfield MJ. Genes for blood pressure: an opportunity to understand hypertension. Eur Heart J 2013;34:951961.

47. International Consortium for Blood Pressure Genome-Wide
Association Studies, Ehret GB, Munroe PB, Rice KM, Bochud $\mathrm{M}$, Johnson $\mathrm{AD}$, et al. Genetic variants in novel pathways influence blood pressure and cardiovascular disease risk. Nature 2011;478:103-109.

48. Simino J, Shi G, Bis JC, Chasman DI, Ehret GB, Gu X, et al. Geneage interactions in blood pressure regulation: a large-scale investigation with the CHARGE, Global BPgen, and ICBP Consortia. Am J Hum Genet 2014;95:24-38.

49. Falcone GJ, Biffi A, Devan WJ, Jagiella JM, Schmidt H, Kissela $\mathrm{B}$, et al. Burden of risk alleles for hypertension increases risk of intracerebral hemorrhage. Stroke 2012;43:2877-2883.

50. Schunkert H, König IR, Kathiresan S, Reilly MP, Assimes TL, Holm H, et al. Large-scale association analysis identifies 13 new susceptibility loci for coronary artery disease. Nat Genet 2011; 43:333-338.

51. Dichgans M, Malik R, König IR, Rosand J, Clarke R, Gretarsdottir $\mathrm{S}$, et al. Shared genetic susceptibility to ischemic stroke and coronary artery disease: a genome-wide analysis of common variants. Stroke 2014;45:24-36.

52. Lindgren A, Lovkvist H, Hallstrom B, Hoglund P, Jonsson AC, Kristoffersson $\mathrm{U}$, et al. Prevalence of stroke and vascular risk factors among first-degree relatives of stroke patients and control subjects. A prospective consecutive study. Cerebrovasc Dis 2005;20:381-387.

53. Seshadri S, Beiser A, Pikula A, Himali JJ, Kelly-Hayes M, Debette $S$, et al. Parental occurrence of stroke and risk of stroke in their children: the Framingham study. Circulation 2010;121: 1304-1312.

54. Brass LM, Isaacsohn JL, Merikangas KR, Robinette CD. A study of twins and stroke. Stroke 1992;23:221-223.

55. Bak S, Gaist D, Sindrup SH, Skytthe A, Christensen K. Genetic liability in stroke: a long-term follow-up study of Danish twins. Stroke 2002;33:769-774.

56. Gaist D, Pedersen NL, Koskenvuo M, Bak S, Giampaoli S, Christensen $\mathrm{K}$, et al. Stroke research in GenomEUtwin. Twin Res 2003;6:442-447.

57. Hwang JY, Aromolaran KA, Zukin RS. Epigenetic mechanisms in stroke and epilepsy. Neuropsychopharmacology 2013;38:167182.

58. Qureshi IA, Mehler MF. Emerging role of epigenetics in stroke: part 1: DNA methylation and chromatin modifications. Arch Neurol 2010;67:1316-1322.

59. Qureshi IA, Mehler MF. The emerging role of epigenetics in stroke: II. RNA regulatory circuitry. Arch Neurol 2010;67:14351441.

60. Schweizer S, Meisel A, Märschenz S. Epigenetic mechanisms in cerebral ischemia. J Cereb Blood Flow Metab 2013;33:13351346. 
61. Ramos-Cejudo J, Gutiérrez-Fernández M, Rodríguez-Frutos B, Expósito Alcaide M, Sánchez-Cabo F, Dopazo A, et al. Spatial and temporal gene expression differences in core and periinfarct areas in experimental stroke: a microarray analysis. PLoS One 2012; 7:e52121.

62. Qureshi IA, Mehler MF. Emerging themes in epigenetics: implications for understanding and treating nervous system disorders. Epigenomics 2010;2:345-349.

63. Zaleska MM, Mercado ML, Chavez J, Feuerstein GZ, Pangalos MN, Wood A. The development of stroke therapeutics: promising mechanisms and translational challenges. Neuropharmacology 2009;56:329-341.

64. Pearson-Fuhrhop KM, Minton B, Acevedo D, Shahbaba B, Cramer SC. Genetic variation in the human brain dopamine system influences motor learning and its modulation by L-Dopa. PLoS One 2013;8:e61197.

65. Qin L, Jing D, Parauda S, Carmel J, Ratan RR, Lee FS, et al. An adaptive role for BDNF Val66Met polymorphism in motor recovery in chronic stroke. J Neurosci 2014;34:2493-2502.

66. Cramer SC, Procaccio V; GAIN Americas; GAIN International Study Investigators. Correlation between genetic polymorphisms and stroke recovery: analysis of the GAIN Americas and GAIN International Studies. Eur J Neurol 2012;19:718724.

67. Aberg ND, Olsson S, Aberg D, Jood K, Stanne TM, Nilsson $\mathrm{M}$, et al. Genetic variation at the IGF1 locus shows association with post-stroke outcome and to circulating IGF1. Eur J Endocrinol 2013;169:759-765.

68. Maguire J, Thakkinstian A, Levi C, Lincz L, Bisset L, Sturm J, et al. Impact of COX-2 rs5275 and rs20417 and GPIIIa rs5918 polymorphisms on 90-day ischemic stroke functional outcome: a novel finding. J Stroke Cerebrovasc Dis 2011;20:134-144.
69. Biffi A, Anderson CD, Jagiella JM, Schmidt H, Kissela B, Hansen BM, et al. APOE genotype and extent of bleeding and outcome in lobar intracerebral haemorrhage: a genetic association study. Lancet Neurol 2011;10:702-709.

70. Devan WJ, Falcone GJ, Anderson CD, Jagiella JM, Schmidt H, Hansen BM, et al. Heritability estimates identify a substantial genetic contribution to risk and outcome of intracerebral hemorrhage. Stroke 2013;44:1578-1583.

71. Lindgren A, Bevan S, Fernandez-Cadenas I, Jern C, JimenezConde J, Lee J-M, Lemmens R, et al. GISCOME - genetics of ischaemic stroke outcome study. Cerebrovasc Dis 2014;37 (Suppl 1):285.

72. Fernández-Cadenas I, Del Río-Espínola A, Giralt D, DominguesMontanari S, Quiroga A, Mendióroz M, et al. IL1B and VWF variants are associated with fibrinolytic early recanalization in patients with ischemic stroke. Stroke 2012;43:2659-2665.

73. del Río-Espínola A, Fernández-Cadenas I, Giralt D, Quiroga A, Gutiérrez-Agulló M, Quintana M, et al. A predictive clinicalgenetic model of tissue plasminogen activator response in acute ischemic stroke. Ann Neurol 2012;72:716-729.

74. Furie B. Do pharmacogenetics have a role in the dosing of vitamin K antagonists? N Engl J Med 2013;369:2345-2346.

75. Falcone GJ, Radmanesh F, Brouwers HB, Battey TW, Devan WJ, Valant V, et al. APOE $\varepsilon$ variants increase risk of warfarinrelated intracerebral hemorrhage. Neurology 2014;83:11391146.

76. Paré G, Eriksson N, Lehr T, Connolly S, Eikelboom J, Ezekowitz $\mathrm{MD}$, et al. Genetic determinants of dabigatran plasma levels and their relation to bleeding. Circulation 2013;127:1404-1412.

77. Chan NC, Eikelboom JW, Ginsberg JS, Lauw MN, Vanassche $\mathrm{T}$, Weitz JI, et al. Role of phenotypic and genetic testing in managing clopidogrel therapy. Blood 2014;124:689-699. 